\title{
Central Hemodynamic and Regional Blood Flow Changes in the Newborn with Right Ventricular Hypertension
}

\author{
JAQUES BELIK, KEN BARON, AND R. BRUCE LIGHT \\ Departments of Pediatrics, Anesthesia and Medicine, University of Manitoba, Winnipeg, Manitoba, Canada
}

\begin{abstract}
To evaluate the central hemodynamic and regional blood flow changes associated with right ventricular hypertension in the newborn, 13 anesthetized, mechanically ventilated piglets less than $3 \mathrm{~d}$ old were acutely instrumented to permit measurements of central vascular pressures, cardiac output, and regional blood flow (radiolabeled microsphere technique). After initial measurements, right ventricular afterload was progressively increased by means of a pulmonary arterial mechanical occluder until right-to-left foramen ovale shunt was observed. An increase in pulmonary arterial pressure from $32 \pm 2$ to $55 \pm 3 \mathrm{~mm} \mathrm{Hg}$ was associated with a decrease in $\mathrm{PaO}_{2}$ from $364 \pm 16$ to $88 \pm 9 \mathrm{~mm} \mathrm{Hg}$ and an increase in the shunt fraction from $13 \pm 1$ to $28 \pm 1 \%(p<0.01)$ during ventilation with oxygen. Right ventricular hypertension induced a significant decrease in systemic arterial pressure from $79 \pm 3$ to $63 \pm 4 \mathrm{~mm} \mathrm{Hg}$, and left ventricular cardiac output from $156 \pm 10$ to $112 \pm 11 \mathrm{~mL} \cdot \mathrm{min}^{-1} \cdot \mathrm{kg}^{-1}(p<$ 0.01 , likely secondary to a reduction in lefe ventricular compliance. Oxygen delivery to the brain and heart were unaffected, due to a substantial increase in regional blood now, but a significant reduction in delivery to the bowel and kidneys were observed. Contrary to what has been reported in the adult, myocardial blood flow to the right ventricle increased during hypertension. Metabolic acidosis was seen in all animals and the changes in serum bicarbonate and whole body oxygen consumption were directly related to the magnitude of decline in systemic $\mathrm{O}_{2}$ delivery. In conclusion, right ventricular hypertension with right-toleft foramen ovale shunt is associated with a significant reduction in systemic arterial pressure and left ventricular cardiac output in the newborn. These changes coupled with a further decrease in arterial oxygen content secondary to the increase in shunt fraction, place the newborn animal with right ventricular hypertension at great risk for hypoxic-ischemic organ injury. (Pediatr Res 26:548-553, 1989)
\end{abstract}

\section{Abbreviations}

RVH, right ventricular hypertension

$Q_{s} / Q_{r}$, shunt fraction

$\mathrm{DO}_{2}$, systemic oxygen delivery

$\mathrm{VO}_{2}$, whole body oxygen consumption

$\mathrm{LV} \mathrm{dP/dt,} \mathrm{first} \mathrm{derivative} \mathrm{of} \mathrm{left} \mathrm{ventricular} \mathrm{pressure} \mathrm{with}$ respect to time

$\mathbf{P}_{\text {SA }}$, systemic arterial pressure

$\mathbf{P}_{\mathrm{PA}}$, pulmonary arterial pressure

$\mathbf{P}_{\mathrm{RA}}$, right atrial pressure

Correspondence Jaques Belik, M.D., Health Sciences Centre, Room WR 004, 820 Sherbrook Stree1, Winnipeg, Manjtoba, R3A I R9 Canada.

Supported by grants from the Children's Hospital of Winnipeg Research Foundation and Manitoba Health Research Council
$P_{L A}$, left atrial pressure

$\dot{Q}_{\mathrm{P}}$, pulmonary blood flow

$\hat{Q}_{\text {s, systemic cardiac output }}$

PPHN, persistent pulmonary hypertension syndrome

Because the left and right ventricles are anatomically and functionally related, an increase in the ventricular afterload in one compartment will perturb the function of the other ventricle. RVH in adult subjects is associated with a significant reduction in $P_{S A}$ and left ventricular output (1). These changes are related not only to the decrease in left ventricular preload, accounted for by the reduced $\dot{Q}_{p}$, but also to an impairment in left ventricular systolic function (2).

During the immediate neonatal period, there are theoretical reasons why an increase in right ventricular afterload may not necessarily lead to the central hemodynamic changes observed in adult subjects. First, because of the higher afterload normally seen during fetal life, the right ventricle has a much larger muscle mass relative to the adult. Second, the foramen ovale is only functionally closed early in life, and an increase in right ventricular afterload sufficient to produce elevated filling pressures will lead to a right-to-left shunt at the atrial level, which might leave left ventricular preload relatively unaffected (3). However, our previous observation, that $\mathbf{P}_{S A}$ is significantly reduced when $R V H$ is acutely induced in the piglet (4), suggests that an increased right ventricular afterload can compromise left ventricular function in the newborn.

In the human newborn, RVH is commonly seen in the first few hours of life and the interaction between the right and left ventricles may have important clinical implications, as systemic hypotension and multiple organ dysfunction are commonly seen in infants with the PPHN (5). The factors contributing to these changes during pulmonary hypertension are not well understood, but could conceivably be related to left ventricular dysfunction leading to reduced cardiac output and $\mathrm{DO}_{2}$.

Because limited data are available to adequately address this issue, in our study we sought to determine the central hemodynamic changes leading to systemic arterial hypotension during RVH in the newborn pig. Furthermore we wished to establish what secondary effects on systemic and regional oxygen delivery result from RVH severe enough to cause intracardiac right-toleft shunt in this newborn animal.

\section{MATERIALS AND METHODS}

Surgical Preparation. Thirteen piglets $1-3 \mathrm{~d}$ of age and with a mean wt of $2.0 \pm 0.1 \mathrm{~kg}$, kept with the sow until the day of the experiment, were studied. Before surgery, the animals received pentobarbital sodium ( $20 \mathrm{mg} / \mathrm{kg}$ intraperitoneally), and a single induction dose of ketamine $(10 \mathrm{mg} / \mathrm{kg}$ intramuscularly). Initially, 
the trachea was cannulated and the animals were connected to an infant mechanical ventilator (Baby Bird, Bird Corporation, Palm Springs, CA). Pancuronium bromide $(0.2 \mathrm{mg} / \mathrm{kg}$ intravenously) was administered, and the ventilator settings were adjusted to ensure normocapnia. The details of the surgical preparation have been previously described (4). Briefly, a 4 Fr catheter, with an incorporated oxygen-electrode, was advanced into the abdominal aorta through the femoral artery and attached to a monitor to continuously read in vivo $\mathrm{PaO}_{2}$ (Searle catheter and monitor; Cardiomed Supplies, Gormley, Ontario, Canada), whereas a 5 Fr right atrial catheter was positioned by femoral venous access. After a left lateral thoracotomy and ductus arteriosus ligation, a 5 Fr catheter was advanced into the main pulmonary artery by direct puncture immediately distal to the pulmonic valve and secured by means of a purse-string to the vessel wall. After careful dissection of the pulmonary artery, a silk band was placed distal to the ductus arteriosus and connected to a mechanical device that allowed for progressive vessel occlusion. The device consisted of a silk snare extruding from a plastic tubing (diameter $=3 \mathrm{~mm}$; length $5 \mathrm{~cm}$ ) connected, outside the chest, to a screw, for adjustment of the snare's tension. A precalibrated electromagnetic flow probe was placed around the main pulmonary artery adjacent to the pressure catheter [Carolina Medical Electronics, Inc. (King, NC) flowmeter and probe]. Finally, a left atrial catheter was inserted via the left atrial appendage, and the left chest incision was approximated and covered with a plastic sheet. Care was taken to completely reexpand the left lung after completion of the surgery.

For the duration of the experiment the animals were ventilated with oxygen $\left(\mathrm{FiO}_{2}=1\right)$ to ensure normoxemia after the induction of right-to-left shunt. Positive end expiratory pressure $(3 \mathrm{~cm}$ $\mathrm{H}_{2} \mathrm{O}$ ) was added to the ventilator to maintain lung inflation and was increased to $10 \mathrm{~cm} \mathrm{H}_{2} \mathrm{O}$ for a few seconds, on a regular basis during the experiment, to prevent any lung atelectasis. The peak inspiratory pressure was set at $12-15 \mathrm{~cm} \mathrm{H}_{2} \mathrm{O}$ and maintained constant during the experiment.

Rectal temperature was monitored continuously (Yellow Springs telethermometer; Yellow Springs Instruments, Yellow Springs, $\mathrm{OH}$ ), and maintained at $38.5 \pm 0.5^{\circ} \mathrm{C}$ by means of an overhead electric heating device. End tidal $\mathrm{CO}_{2}$ concentration was measured continuously at the endotracheal tube (Beckman OM-11) (Beckman Instruments, Inc., Fullerton, CA) and the ventilator rate was adjusted to maintain the $\mathrm{PaCO}_{2}$ stable at 40 $\mathrm{mm} \mathrm{Hg}$. The catheters were connected to Gould pressure transducers (P23xL, Copenhagen, Denmark) to allow for continuous recording of $\mathrm{P}_{\mathrm{SA}}, \mathrm{P}_{\mathrm{PA}_{\mathrm{A}}}, \mathrm{P}_{\mathrm{RA}}, \mathrm{P}_{\mathrm{LA}}, \mathrm{Q}_{\mathrm{P}}$, rectal temperature, and $\mathrm{PaO}_{2}$. Mean pressures were obtained by electrical integration, and the heart rate was extracted from the pressure tracing.

The animals were allowed a stabilization period of at least $1 \mathrm{~h}$ before any experimentation was initiated. Anesthesia was maintained by hourly pentobarbital sodium administration (3-5 $\mathrm{mg} /$ $\mathrm{kg}$ intravenousiy), and pancuronium bromide $(0.05 \mathrm{mg} / \mathrm{kg}$ intravenously) was repeated when spontaneous breathing was noted.

Arterial blood gas measurements and $\mathrm{pH}$ were made using a microelectrode technique ( $0.2 \mathrm{~mL}$ of blood) on a model ABL-3 Radiometer blood gases analyzer (Radiometer, Copenhagen, Denmark), and the standard bicarbonate, as calculated by the analyzer, was used. Blood oxygen saturation and $\mathrm{Hb}$ determination were measured by micro sample $(0.1 \mathrm{~mL})$ in a model OSM-2 Radiometer. The arterial and mixed venous oxygen content were calculated according to the standard formula: blood $\mathrm{O}_{2}$ content $=1.36 \times \mathrm{Hb} \times \mathrm{SaO}_{2}+\mathrm{PaO}_{2} \times 0.003$ where $\mathrm{Hb}=\mathrm{Hb}$ concentration and $\mathrm{SaO}_{2}=$ blood oxygen saturation. These data were used to calculate $\mathrm{Q}_{\mathrm{S}} / \mathrm{Q}_{\mathrm{T}}$ according to the following formula:

$$
\mathrm{Q}_{\mathrm{S}} / \mathrm{Q}_{\mathrm{T}}=\frac{\mathrm{CcO}_{2}-\mathrm{CaO}_{2}}{\mathrm{CcO}_{2}-\mathrm{CvO}_{2}}
$$

where $\mathrm{CaO}_{2}$ is arterial oxygen content, $\mathrm{CvO}_{2}$ is mixed venous oxygen content and $\mathrm{CcO}_{2}$ is the oxygen content of blood equilibrated with ideal alveolar gas. The $\mathrm{O}_{2}$ tension of ideal alveolar gas used to calculate $\mathrm{CcO}_{2}$ was taken from the alveolar gas equation. $\dot{\mathrm{DO}}_{2}$ was calculated as $\dot{\mathrm{Q}}_{5} \times \mathrm{CaO}_{2}$, and $\dot{\mathrm{VO}}_{2}$ as the $\left(\mathrm{CaO}_{2}-\mathrm{CvO}_{2}\right) \times \dot{\mathrm{Q}}_{s}$. Regional $\mathrm{O}_{2}$ delivery was calculated as the organ blood flow $\times \mathrm{CaO}_{2}$.

Systemic vascular resistance was calculated as the $\left(P_{S A}-P_{R A}\right) /$ $\dot{Q}_{s}$ and the pulmonary vascular resistance was choosen to estimate the right ventricular afterload and was calculated as $\left(\mathrm{P}_{\mathrm{PA}_{\mathrm{A}}}-\mathrm{P}_{L_{\mathrm{A}}}\right) / \mathrm{Q}_{\mathrm{P}}$. Regional vascular resistance was calculated as the $P_{S A}$ divided by organ blood flow.

Measurement of organ blood flow. Blood flow to the different organs was measured with the tracer microsphere technique Microspheres $\left(15 \pm 1 \mu\right.$ ) labeled with ${ }^{141} \mathrm{Ce},{ }^{85} \mathrm{Sr}$ or ${ }^{46} \mathrm{Sc}(3 \mathrm{M}, \mathrm{St}$. Paul, MN) were used. Stock solutions were sonicated for $5 \mathrm{~min}$ and shaken vigorously on a vortex mixer for $2-5 \mathrm{~min}$. Approximately $0.7-1.2 \times 10^{6}$ microspheres were placed into specially prepared injection vials and shaken again on a vortex mixer before injection. The contents of the injection vial were flushed into the left atrium over a period of 15-30 s. Reference arterial blood was withdrawn from a catheter in the thoracic aorta, for $10 \mathrm{~s}$ before, during, and for $60 \mathrm{~s}$ after the microsphere injection at a rate of $1.03 \mathrm{~mL} / \mathrm{min}$.

At the end of the experiment, the animal was killed by an injection of concentrated potassium chloride, and the brain, heart, kidneys, bowel (including duodenum, small and large bowel) and a portion of the anterior limb muscle were removed. The heart was further dissected to separate the right and left ventricular free wall myocardium. All tissues were weighed and placed into counting vials. The remaining carcass was carbonized and a weighed sample also placed into counting vials as were the reference blood samples. Counting vials were filled to a ht of less than $2.5 \mathrm{~cm}$ to minimize geometrical counting error.

Tissue and reference blood samples were counted for $3 \mathrm{~min}$ with a multichannel $\gamma$-counter (Compugama, LKB-Produkter AB, Bromma, Sweden). Nuclide separation was performed using standard methods for differential spectrometry (6). Blood flow was calculated with the formula $Q=A t \cdot Q r \cdot \mathrm{Ar}^{-1} \cdot \mathrm{wt}^{-1} \cdot 100$, where $\dot{Q}$ is flow to tissue ( $\mathrm{mL} \cdot \mathrm{min}^{-1} \cdot 100 \mathrm{~g}^{-1}$ ) and $\mathrm{Qr}, \mathrm{At}, \mathrm{Ar}$, and $w$ are the reference blood withdrawal rate, activity of the tissue, activity of the reference blood and the tissue wt, respectively. Left ventricular output was calculated by entering the total animal activity and body wt in $\mathrm{kg}$, in the above formula. Bowel flows were expressed as $\mathrm{mL} \cdot \mathrm{min}^{-1} \cdot 100 \mathrm{~g}^{-1}$ of wet tissue wt.

Myocardial contractility measurement. Left ventricular pressure was recorded in five animals with a $5 \mathrm{~F}$ Millar transducer advanced through the ventricular wall away from the mitral valve, and secured in place with silk sutures. The $L V \mathrm{dP} / \mathrm{dt}$, measured as the maximum rate of change of pressure during early systole, was generated with a Hewlett-Packard 8814A (Hewlett-Packard $\mathrm{Co}$., Palo Alto, $\mathrm{CA}$ ) derivative computer and continuously recorded on paper. This parameter, although not ideal, has been previously used in newborn animals as a measure of myocardial contractility (7).

Experimental procedure. Initially, baseline measurements of $P_{P_{A}}, P_{S A}, P_{R_{A}}, P_{L A}, L V d P / d t$, and $Q_{P}$ were obtained. A left atrial radionuclide microsphere injection was performed to measure $Q_{\text {s }}$ and regional blood flow distribution. After the initial measurements, the pulmonary artery was progressively constricted, until the distal aorta $\mathrm{PaO}_{2}$ fell below $100 \mathrm{~mm} \mathrm{Hg}$, indicating the presence of significant right-to-left foramen ovale shunting (RVH). Final measurements, similar to the initial ones, were repeated during $\mathrm{RVH}$. Arterial and venous blood gases, oxygen saturation, and $\mathrm{Hb}$ were obtained initially and during $\mathrm{RVH}$.

Statistical analysis. All data are reported as mean \pm SEM. Differences between means were analyzed by paired Student's $t$ test. Least square correlation analysis was used to evaluate the linear regression relationship between $\dot{\mathrm{DO}}_{2}, \dot{\mathrm{VO}} 2$, and serum $\mathrm{HCO}_{3} . p<0.05$ was considered significant. 